\title{
Cognitive Moral Development and Its Relevance in Establishing Moral Integrity in Organization
}

Anggara Wisesa*

School of Business and Management, Bandung Institute of Technology, Bandung, Indonesia

*Corresponding author: anggara@sbm-itb.ac.id

\begin{abstract}
Integrity is one of the most important values in organization's life. A common approach used in defining integrity is to associate the concept with particular ethical behavior, so often the approach taken is to encourage every individual in the organization to act in accordance with the expected behaviors. Integrity is associated with decision-making process in which the development of moral cognitive influences. In reality, not all stages of cognitive moral development are supporting the establishment of integrity. Only the sixth stage of moral development which is oriented to universal moral values that can support the formation of integrity. By using philosophical critical analysis approach, this paper aims to explain conceptually how cognitive moral development plays role in the formation of integrity of the self and the consequence in shaping culture in organization. It concludes that creating organizational culture of integrity needs not only to think about how to shape the behavior of members of the organization in line with the behavior expected by the organization, but at the same time how to form moral consciousness oriented to universal moral values.
\end{abstract}

Keywords: Integrity; morality; moral cognitive development; organizational culture; value

(C) 2016 Penerbit UTM Press. All rights reserved

\subsection{INTRODUCTION}

Ansoff (1979, in Stead and Stead, 2000) showed that throughout the last quarter of the 20th century there was an increase in demand for business organizations to participate in social, politics, and ethics lives as part of the community. Nowadays, companies face more and more strategic problems related to these three issues. Ever-changing environment forces the organization to continue to develop strategies to survive, and one of the focuses is in moral dimension (Stead and Stead, 2000).

Discussing about morality in the organization, integrity has become one of the important moral notion that are discussed and applied continuously in the organization. Many organizations incorporate these terms in their code of ethics as reference in acting for its members, ranging from top management to the lowest level. Duggar (2011) emphasizes the importance of integrity, both in the individual and corporate level. Corporate that applies culture of integrity tends to be leader in the industry by exceeding the performance of other companies, including its long-term financial performance. This is an incentive for them to implement integrity in the organizations.

In the organizational context, the term integrity has penetrated into it, shaping organizational values and culture, communication in it, and the commitment of every person to apply ethics in every their activity (Weiss, 2003). Integrity is also a determinant of trust in interindividual relations in the organization (Hosmer, 1995; Mayer, Davis, \& Schoorman, 1995), even more it becomes work value that is most needed in organizational life (Askun, Oz, and Aşkun, 2010).

Not only limited in the context of business organization, integrity is also held as an important notion in other aspects of life, such as education, health, government, and others. In the context of governance, for example, integrity is used to refer to the commitment to carry out corruption free policy. Integrity is shown as an ideal, a trait that is both attached and incorporated as a good moral behavior.

\subsection{CONCEPTUAL FRAMEWORK}

Attempts to define integrity also often direct integrity to certain principles and values, such as honesty, objectivity, adherence to the rules, consistency between words and deeds, and so forth. The value of integrity is often expressed in a flawless reputation and correlated with confidence.

Associated with the conception of integrity as a form of consistency, some people identifies integrity as conscience, moral accountability, moral commitment, and consistency of the moral person (Paine, 1994) between the behaviors they manifested and values or certain principles (Yukl \& Van Fleet, 1992; Mayer, Davis, \& Schoorman, 1995; Becker, 1998). In the theory of leadership, integrity is also used to describe a person's ability to translate his words into action (McShane \& Von Glinow, 2003), in other words there is consistency between words and 
actions. It is also necessary to have commitment to do so. Commitment and consistency have become the criteria to be considered to realize the integrity of it.

Moreover, Trevinyo-Rodríguez (2007) describes integrity within individual, social, and organizational frameworks. Within this framework, integrity should be translated as whether the context refers to the values held by one self, community, or organization in which a person resides. It makes integrity relative depends on the scope of one's role. One important point of this concept is that integrity includes one's commitment to a principle.

Researches in the field of employee selection uncovers that integrity test is performed by measuring several variables such as honesty and moral reasoning (Berry, Sackett, Wiemann, 2007; Ones, Viswesvaran, Schmidt, 1995). Honesty seems to be an integral part of discussion about integrity. In the literature of organization and human resources, integrity is commonly associated with the individual honesty (Yulk \& Van Fleet, 1992). The same was done by Butler and Cantrell (1984, in Hosmer, 1995) who defines integrity as someone's trustworthy and honest reputation to explain the term "trust" in the context of organization.

Integrity is also placed as the core of virtue ethics as initiated by Solomon (1992) by calling integrity not only as individual autonomy and togetherness, but also loyalty, harmony, cooperation, and trustworthy. However, can it be equated with honesty integrity or trustworthiness? DeGeorge (1993) argues that acting with integrity and acting ethically are synonymous, although literally there is no moral connotation in it.

\subsection{COGNITIVE MORAL DEVELOPMENT}

The conception of integrity as a particular form of ethical action has drawbacks. In explaining whether an action is ethical or not, the same action performed can be driven by different values or motivations. For example, not cheating behavior done by students is not always because they uphold the value of honesty. Most of them do not cheat because of fear of getting zero mark as consequence, friends, responsibility as a student, respecting intellectual property rights, etc. (Wisesa, 2009). That is, whether or not a person is full of integrity cannot be measured just by looking at the exhibited behavior.

Acting with integrity at its core is a form of decision-making process. Action is just one of many elements involved in the decisionmaking process. Conditions of integrity requires action state that is consistent with certain principles (Putman, 1996), thus reflects unified as a whole in human beings, the harmonious unity between action and commitment, and even between commitments in different contexts (Furrow, 2005; Dunn, 2009). Integrity occurs when the implementation of the actions taken are consistent with the moral principles used as guidance in making decisions on ethical reasoning stage in which moral consciousness takes dominant role. That is why the consistency of the moral principle is referred as moral integrity. The existence of commitment or orientation to this principle is explained for example by Lawrence Kohlberg's Theory of Cognitive Moral Development.

Kohlberg (1995) emphasizes the importance of attention to this moral consciousness to understand how ethical decisions are taken and also ethical reasons why a person takes certain decisions (Rest, 1986; Trevino, 1992). One fundamental idea of this concept is that moral sense is not determined by feelings, but by intellectual ability, namely the ability to grasp and understand something rationally (MagnisSuseno, 2000). In explaining this theory, Kohlberg did not talk about certain moral principles, did not talk about what is right and not morally, but rather examined the competence to provide ethical reasoning. He did not say whether action of a grandmother stealing milk for the sake of her grandchildren who was in hunger, for instance, is ethical or unethical, but whether the act of stealing milk was approved or not approved adequately justified (Arbuthnot \& Faust, 1980).

For Kohlberg, there are certain moral considerations underlying someone's action that supposes cognitive abilities in making decisions. How one acts or reacts when he is facing moral dilemma is the result of complex interactions between variables such as individual characteristics (including personal values) and the stage of moral development (Robbins, 2005). Research conducted by Kohlberg also showed that there is certain level or stage of development presupposes the existence of a person's cognitive abilities in building ethical argument for his actions. The result is typology of human moral cognitive abilities that he set into six stages of moral cognitive development, which consists of two pre-conventional stages, two conventional stages, and two post-conventional stages as can be seen in Table 1 . Altogether there are six stages of development. Each of these levels and phases can be seen as particular moral thinking, different view of socio-moral world (Crain, 1985).

In the pre-conventional level, which includes stages 1 and 2 , an individual understands the sense of right and wrong based on consequences which receives, for example, punishment, reward, or personal fulfillment. In summary, moral awareness in the first development stage is described as orientation to compliance and penalties. In this first phase, someone associates good and bad of an action with the physical consequences of he gets upon the action. When a person receives punishment for his action, then he understands that his action is wrong. Compared with the first stage mode of reasoning, the second stage represents what is good in order to fulfill one's own interests. People begin to understand that other people have their own individual needs and social organization is built on the basis of balanced exchange between the interests of a person with the interests of others. Both first and the second stage reasoning are egocentric.

In the conventional level, stage 3 and stage 4, the individual understands morally true or not as suitability between decision taken and other people's expectations of him, both in the context of interpersonal relationships (phase 3) and the implementation of someone's roles within wider and abstract social system (stage 4). In the third stage, a good decision is a decision that accommodates expectations of others, do what is "good" in the eyes of others, what is approved by others, behave in accordance with other person's request, or be loyal and trustworthy to a close group. Social perspective at this stage indicates awareness of other's expectations and mutual agreement, feelings or perspectives of others, and that the interest of social group is more important than own self-interest. In the fourth stage, what is good is acting in accordance with obligations in social life with the aim of maintaining social group as a whole. He who is in the fourth stage understands that without the same legal standards, human life would be chaotic, where he has been able to position himself as part of the wider community. Law is regarded as collateral for interpersonal interaction, comfort, and personal rights.

In the post-conventional moral reasoning level, namely stages 5 and 6 , individual moves to deeper and more universal moral understanding. In the fifth stage, one realizes that there are relative rules and non-relative (absolute) rights and values. Relative rules exist in the context of particular community groups and should be upheld because it is the basic for social contract. On the other hand, the nonrelative rights and the values, for example the right to life and the right to freedom, must be respected regardless of public opinion or the will 
of the majority. In the sixth stage, one starts to switch to universal moral principles, not because the principles are approved communally in the social contract, but because they come from the equality of human rights and respect for the humanity and human dignity. A critical factor in determining what is ethically right is universal moral principle that is consistent, comprehensive, and logical that exists in the conscience, and is not based on fear and guilt feelings. It is associated with autonomous judgment in which one must determine whether an action is in line with what is believed to apply universally.

Table 1 Stages of moral development

\begin{tabular}{|l|l|}
\hline \multicolumn{1}{|c|}{ Level of Moral Development } & \multicolumn{1}{c|}{ Stage of Reasoning } \\
\hline Preconventional & Stage 1: Right is obedience to power and avoidance of punishment \\
\cline { 2 - 2 } & $\begin{array}{l}\text { Stage 2: Right is taking responsibility and leaving others to be } \\
\text { responsible for themselves }\end{array}$ \\
\hline Conventional & $\begin{array}{l}\text { Stage 3: Right is being considerate: "uphold the values of other } \\
\text { adolescents and adults' rules of society" }\end{array}$ \\
\cline { 2 - 2 } & $\begin{array}{l}\text { Stage 4: Right is being good, with the values and norms of family and } \\
\text { society at large }\end{array}$ \\
\hline Postconventional & $\begin{array}{l}\text { Stage 5: Right is finding inner "universal rights" balance between self- } \\
\text { rights and societal rules - a social contract }\end{array}$ \\
\cline { 2 - 2 } & $\begin{array}{l}\text { Stage 6: Right is based on a higher order of applying principles to all } \\
\text { human-kind; being non-judgmental and respecting all human life }\end{array}$ \\
\hline
\end{tabular}

Source: Adapted from Kohlberg, 1986: 57-58

\subsection{COMMITMENT TO MORAL VALUES}

If moral consciousness is divided into so many stages, does integrity have multiple meanings in accordance with each stage of moral consciousness? Are students who do not cheat when doing the test for fear of zero score can be said full of integrity (reasoning typically stage 1 of moral development)? Whether an official who refuses to accept bribes because he is bound by oath of his institution (stage 4) can be said full of integrity? These are important questions that need to be considered to answer how moral integrity should be interpreted.

In objectivistic ethics, integrity is defined as loyalty to the principles and values that are rational (Peikoff, 1991). Although objectivism itself is actually got a lot of critics when it is used as the basic foundation for the development of ethics due to its egoistic nature (see Rand, 1964; and objections against objectivism in Barry \& Stephens, 1998), the axiom of objectivism can help to develop the concept of integrity. In essence, objectivism stressed that the reality of being is separated from human consciousness and the human whose consciousness touches reality by his intellectual through the formation process of concepts and logic. Because he has consciousness and reason, human has ability to think or not to think, and can therefore choose alternatives of action.

The first thing that can be drawn from the conception is that integrity is a form of loyalty, the courage for someone to hold the universal moral principles and values. The moral principle is the norm, the moral rules that encourage or forbid someone to do something. The basis of moral principle is moral value. Moral principle of not to kill emerges from the idea that life is something universally moral worth. The second thing is that the integrity is not about words alone, but also reflecting the action in line with moral values and principle that is universal and rational (Becker, 1998). Here, loyalty to principle or value is realized in the form of action, where that loyalty is shown as someone's determination to act in line with the principles or values that he holds. However, this does not mean that there is no possibility for him to change, even a person has moral obligation to change his view when what he holds is wrong (Peikoff, 1991; Becker, 1998). The third, integrity is not only about acting in line with principle or value, but with objective principle or value that is morally justified. This justification must come as conclusion obtained through logical principle (Peikoff, 1991), not from mere emotion.

The moral principle and value is something objective that its conceptualization is built through real experiences and sensory perception of objects and actual conditions (Becker, 1998). That is why integrity requires more than just loyalty to moral principle and value that is believed true by individual or approved by community or organization. Integrity is not just about acting in accordance with the value received by the individual, community, or organization (Mayer, Davis, \& Schoorman, 1995; Trevinyo-Rodríguez, 2007), but refers to the universal moral principle that can be justified rationally, where the justification criteria is objective. Subjective opinion, in individual level, community, or organization, cannot be the basis for moral integrity.

This concept along with the cognitive moral development theory leads to the conclusion that moral integrity can only be fulfilled when the decision and the person's action is based on the understanding of moral principles of the sixth stage of moral development. In this sixth stage, the value orientation to integrity actually leads to universal moral principles that are autonomously selected and used as personal principle to hang on (Wisesa, 2009). In this stage, for example, a student chooses to not cheat not because it is reluctant to accept zero score, or goes along with his friends or because of his obligation as student, or any other, but because of loyalty to the value of honesty. Honesty itself is one of the universal moral values to which moral norms in society and culture refer to. What is ethically correct in the sixth stage is acting in line with the principles held autonomously that covers the entire scope of human beings on the whole period. This universal principle is followed not because approved communally in the social contract, but because it comes from the equality of human rights and respect for humanity and dignity of human being.

How to determine whether an action is in line with what is believed as universally applicable? Kohlberg filed two ethical concepts that are in line with the intended mode in the sixth stage, which are the golden rule and the categorical imperative. The golden rule contains rules that encourage someone to not do to others what he does not want others to do to him. This rule is built on the concept of equality and dignity of all human beings. All persons are equal and have the same value regardless of racial background, ethnicity, age, gender, occupation, status, and more. Therefore, everyone should respect other people at least just as he respects himself. 
The categorical imperative itself is a concept popularized by Immanuel Kant (1785/1996). Although similar to the golden rule, but they are different. The golden rule requires that a person's action is adapted to the standard itself; otherwise the categorical imperative presupposes that applicable standard wherever and whenever. He stated that one should always be treated with full respect for the sake of humanity and dignity, and must be placed as end and as his own self. The point is that the action associated with him should not be placed his self as means for other purposes, but that action must position his self as the final destination of that action. Differences between the golden rule and the categorical imperative can be seen for example in regard of lying. The golden rule can accept lying as ethically in certain situations, but the categorical imperative says that lying is immoral without exception. For Kant, an action considered ethical if it can be universalized.

The typological scheme developed by Kohlberg describes the structures and forms of common ethical reasoning that can be defined individually regardless of ethical decisions and actions taken in the process of ethical decision making. According to Kohlberg, in the moral consciousness there is strong cognitive element. For him, moral awareness is not first determined by mere feelings or even taste, but by intellectual ability, the ability to grasp and understand something. The growth of moral consciousness occurs in the process of widening and deepening the aspects to consider when people give moral judgments. The lower the cognitive moral stage, the narrower the criteria used in providing the moral judgments. Oppositely, as individual increasingly matures, he becomes morally more competent in providing moral judgments (Magnis-Suseno, 2005) .The draw of this theory is that Kohlberg discuss morality without talking about certain moral principles, do not talk about what is morally right and wrong, but rather examine the competence to pass moral judgment. Kohlberg discuss morality impartially.

There is paradigmatic reason underlying this impartiality that can be traced to Jean Piaget, a Swiss philosopher and developmental psychologist, who demonstrated that human ability to perform moral reasoning evolves through specific stages as their cognitive ability develops. Piaget's thought is fundamentally influenced by his background as a biologist, and his interest in the classification of species (especially mollusks) based on morphological variations. Just like various biological species of animals can be classified into categories based on the characteristics of formal structure, it is so with certain structural characteristics in patterns of thought exist in human cognition (Lapsley, 1996). From this perspective, Piagetian stage is a descriptive taxonomy category that classifies formal morphological characters on the level of human epistemic thought patterns. These steps illustrate the kinds of knowledge, diversity, and types of mental operations, but not about personality types (Lapsley \& Narvaez, 2004).

\subsection{UNIVERSAL MORAL VALUES AND ESTABLISHMENT OF MORAL INTEGRITY}

Although Kohlberg's theory of cognitive moral development only maps people's cognitive developmental stage, there is demand that this theory could be used more widely in practical terms, including on the issue of integrity. This challenge is answered by Daniel Putman (1996). He departed from the vagueness of the concept of integrity, particularly those expressed by Mark Halfon (1989) as paradigmatic case of integrity. In his book titled Integrity: A Philosophical Inquiry, Halfon argued that the issue of integrity depends on what he calls "kinds of persons". Unfortunately, according to Putman this term is too vague to definitively show what condition that makes a person full of integrity. Putman then referred to Kohlberg's theory of moral development (and also Carol Gilligan) to explain the "kinds of persons".

Putman concluded that integrity cannot be formed at all stages of cognitive development. A person who is in pre-conventional stage of development has not had mental capability to build integrity because Putman thinks that egocentric behavior (which is typical in preconventional level of development) cannot support the formation of integrity. Egocentric behavior is actually a reflection of the progress of moral development that is still very heteronomous. He who is in the pre-conventional level views that there is other people who is in the hierarchy above him who has power over himself, including in terms of punishment or help him get what he wants. Similarly, moral consciousness in this conventional moral development stage, convention principles to social groups is not yet strong enough to support integrity. Someone who is in this stage is adhering to the values of the group that is outside himself, who determines what is good for him to do. Family, close friends, colleagues, and others are people who are relationally can determine whether he is a good person from their actions, and recognition of them is everything. This shows there are still gaps in interpersonal relationships. Similarly, adherence to the law in the fourth stage does not show yet someone's autonomy in acting. He put himself under the power of the collective society from which the law is born. Consequently, when the value held by the group or society is changing, it is probable that the principle of individual shifts along the change. It means that the individual will be in the flow of social change for the sake of blind obedience to the rules established by the group. This condition is that according to Putman cannot be used as a basis for integrity. He requires that integrity is related to the effort to maintain the unity between his self and the values he holds even though in a difficult situation.

By contrast, the post-conventional development stage can be applied with good integrity. Someone who is in this stage is already able to make decisions autonomously, apart from the influence of other parties. This reflects that he is able to put himself in equal conditions with the others, to build relationships of reciprocity, placing himself equal to others. He is able to see that other people have rights that should be appreciated. He is also able to see that the other person is the same person as himself as a human being. He is able to respect other people truly as human beings with dignity and status, and not as something else. Autonomy is what is needed to establish the integrity. However, Putman said that this autonomy alone is not enough for integrity, but requires action. Integrity is related to the election of moral principle autonomously and to act based on that principle, especially in difficult situation. This means that people need to put commitment and motivation on that principle in their action. Finally, for Putman, integrity will reach its highest level when the person can maintain the balance between virtues, when empathy and generosity meet with a personal commitment to justice.

\subsection{CONCLUSION AND IMPLICATION}

Understanding the meaning of integrity is not enough by just discussing on a scale of behavior exhibited or moral principles held by individual. Integrity includes both. Therefore, the review and evaluation of the integrity must include both an understanding of the moral principle held by individuals and the behavior shown. Moral principle itself must be built on the basis of universal moral values so that the action taken according to the moral principles is really worth ethically. That is why it is not easy to say a person's action as full of integrity. Integrity is not just a term that refers to ethical behavior, but more deeply, integrity presupposes a level of understanding of moral that is 
universal and rationally justifiable. This implies that not every ethical behavior can be judged as an act of integrity, and only ethical behavior performed on the basis of universal moral principles and values that can be candidate as moral integrity.

Code of ethics and corporate rules can indeed be a corridor for behavior of members of the organization in order to create culture of integrity in an organization. However, the application of the code of ethics and rules accompanied by punishment and reward mechanisms has negative effect. Punishment and reward systems are often used to build and strengthen the organization's culture, including pressing unethical behavior by employees. Unfortunately, heavy reliance on punishment and reward system to enforce code of ethics and rules will bring the individuals to the consistency of decisions and actions associated with punishment or certain benefits (pre-conventional stage in Kohlberg's theory of cognitive moral development). Instead of creating an culture of integrity, many organizations are implementing a design that adopted the organizational culture to the low moral reasoning stage by only focusing attention on the behavior that will lead to unethical decision-making and behavior done by employees. Applying moral integrity in the context of the organization thus needs not only to think about how to shape the behavior of members of the organization in line with the behavior expected by the organization, but at the same time how to form moral consciousness oriented to universal moral values.

A person's ability to establish self whose integrity is closely related to his cognitive moral development. How they relate has been described in this paper. However, it does not mean that it is closing the possible for other elements, for example values and motivations, towards the formation of self-integrity.

\section{References}

Arbuthnot, J. B. and Faust, D. (1980). Teaching Moral Reasoning: Theory and Practice, New York: Harper \& Row.

Askun, D., E. U. Oz, and Aşkun, O. B. (2010). "Understanding Managerial Work Values in Turkey". Journal of Business Ethics, 93, 103-114.

Barry, B. and Stephens, C. U. (1998). "Objections to An Objectivist Approach to Integrity". Academy of Management Review, 23(1), 162-169.

Becker, T. E. (1998). "Integrity in Organizations: Beyond Honesty and Conscientiousness". Academy of Management Review, 23(1), 154-161.

Berry, C. M., Sackett, P. R., and Wiemann, S. (2007). "A Review of Recent Developments in Integrity Test Research". Personnel Psychology, 60(2), $271-301$.

Crain, W.C. (1985). Theories of Development, New Jersey: Prentice Hall.

DeGeorge, R. T. (1993). Competing with Integrity in International Business, New York: Oxford University Press.

Duggar, J.W. (2011).“The Role of Integrity in Individual and Effective Corporate Leadership”, Journal of Academic and Business Ethics, 3, 1-7.

Dunn, C.P. (2009). "Integrity Matters", International Journal of Leadership Studies, 5(1), 102-125.

Furrow, D. (2005). Ethics: Key Concepts In Philosophy, New York, New York: Continuum International Publishing Group.

Halfon, M. (1989). Integrity: A Philosophical Inquiry. Philadelphia: Temple University Press.

Hosmer, L. T. (1995). "Trust: The Connecting Link Between Organizational Theory and Philosophical Ethics". Academy of Management Review, 20, 379-403 .

Kant, I. (1996) Groundwork of the Metaphysics of Morals, translated by Mary J. Gregor. Cambridge: Cambridge University Press.

Kohlberg, L. (1986). "The Just Community Approach to Corrections". Journal of Correctional Education. 37, 57-58.

Kohlberg, L. (1995). Tahap-tahap Perkembangan Moral, translated by John de Santo and Agus Cremers, Yogyakarta: Kanisius.

Kohlberg, L., and R. Mayer. (1972). "Development as the Aim of Education", Harvard Educational Review, 42.

Kohlberg, L., C. Levine, and A. Hewer. (1983). Moral Stages: A Current Formulation and a Response to Critics. Buffalo, NY: Karger.

Lapsley, D. K., and D. Narvaez. (2004). "A Social-Cognitive Approach to the Moral Personality", in D. K. Lapsley \& D. Narvaez (Eds.), Moral Development, Self, And Identity. Mahwah, NJ: Erlbaum.

Magnis-Suseno, F. (2000). 12 Tokoh Etika Abad Ke-20, Yogyakarta: Kanisius.

Mayer, R. C., Davis, J. H., and Schoorman, F. D. (1995). “An Integrative Model of Organizational Trust”. Academy of Management Review, $20,709-734$.

McShane, S. L. and M. A. Von Glinow (2003). Organizational Behavior, $2^{\text {nd }}$ ed, Boston: McGraw-Hill Irwin.

Ones, D. S., Viswesvaran, C., and Schmidt, F. L. (1995). "Integrity Tests: Overlooked Facts, Resolved Issues, and Remaining Questions". American Psychologist, 50, 456-457.

Paine, L. S. (1994). "Managing for Organizational Integrity”, Harvard Business Review, March-April, 106-117.

Peikoff, L. (1991). Objectivism: The Philosophy of Ayn Rand, New York: Meridian.

Putman, D. (1996). "Integrity and Moral Development", The Journal of Value Inquiry, 30(1), 237-246.

Rand, A. (1964). The Virtue of Selfishness: A New Concept of Egoism, New York: New American Library.

Rest, J. (1986). Moral Development: Advances in Research and Theory, New York: Prager.

Robbins, S.P. (2005). Organizational Behavior, 11th Ed. New Jersey: Pearson Prentice Hall.

Stead, J. G. and E. Stead. (2000). "Eco-enterprise Strategy: Standing for Sustainability”, Journal of Business Ethics, 24, 313-329.

Trevino, L. K. (1992). "Moral Reasoning and Business Ethics: Implications for Research, Education, and Management". Journal of Business Ethics, 11, 445 - 59.

Trevinyo-Rodríguez, R. N. (2007). "Integrity: A Systems Theory Classification”, Journal of Management History, 13(1), 74-93.

Weiss, J. W. (2003). Business Ethics: A Stakeholder and Issues Management Approach, $3^{\text {rd }}$ ed, Ohio: South-Western.

Wisesa, A. (2009). Orientasi Nilai Integritas dan Keputusan Etis di Balik Pelanggaran Akademik: Pendekatan Perkembangan Kognitif Terhadap Manajemen Perilaku Berbasis Nilai, Tesis, Bandung: Universitas Katolik Parahyangan.

Yukl, G. A. and Van Fleet, D. D. (1992). "Theory and Research on Leadership in Organizations", in Dunnette, M. D. and Hough, L. M. (ed), Handbook of Industrial \& Organizational Psychology, $2^{\text {nd }} e d, 3$. Palo Alto: Consulting Psychologists Press. 